\title{
Using A Project To Add Practicality To Pedagogy
}

Don Yates, (Email: dyates@uscupstate.edu), University of South Carolina Upstate Brian Smith, (Email: tbsmith@uscupstate.edu), University of South Carolina Upstate

\begin{abstract}
In the marketing research class taught at University of South Carolina, Upstate School of Business and Economics, pedagogical emphasis is placed on the marketing research process as it relates to the policies and functions of the business enterprise. Historically, the marketing research project has been used in this undergraduate class to convey the nuances of market research to students. Participating students define the problem or opportunity for their client, determine budgets and timetables, select and design the research instrument(s), collect the data, organize and analyze the data, and present the project findings. A recent project, which involved work for the City of Sunshine, identified, measured, and analyzed specific "quality of life" variables and assessed the impact of the city's revitalization efforts on the perceptions of its citizens. The study targeted three population sectors using questionnaires for data collection. The data was consolidated and analyzed by the students using WebSurveyor's online survey tools. Comparative analysis was also performed using secondary data sources such as city tourism and visitor information, as well as sundry information from previous projects and similar city revitalization plans. The results of their analysis and corresponding conclusions are outlined in this paper.
\end{abstract}

\section{INTRODUCTION}

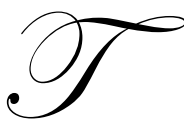

he course SBAD 457 is the marketing research class taught at the USC Upstate School of Business Administration and Economics. Pedagogical emphasis is placed on the marketing research process and its relation to the policies and functions of the business enterprise.

Successful market research requires timely and relevant information. Acquisition of such information is the result of thorough requirements planning, and the subsequent collection and accurate analysis of relevant data. The market research process itself must effectively deal with people and their constantly changing feelings and behaviors influenced by countless subjective factors. This requires continuous communication among constituents often at disparate locations and varying time intervals. It is a back-and-forth collaborative process that is difficult to model in the finite classroom setting. However, an effective tool for teaching undergraduate students the nuances of this process is the practical market research project. Practical research engages the students and compels them to define a problem or opportunity for a real client, determine budgets and timetables, select and design of the research instrument(s), collect, organize and analyze the data, and present of the project findings. Typically the client is a local business or non-profit organization. Previous clients for the marketing research class have included the Interstate Fair, General Motors, the local Mall, a local technical college, and a non-profit alliance of educational institutions.

\section{THE “CITY OF SUNSHINE” MARKET RESEARCH PROJECT}

The project was initiated by the Director of Marketing for the City of Sunshine who contacted the Dean of the Business School. The dean and the professor of marketing research made several informal presentations to this director as well as to the City Manager. The advantage of using the school's students for the research project was emphasized. They then developed and proposed the project along with its objectives to the students. The students discussed the pros and cons of doing the project as a significant percentage of their final grade and then made a unanimous decision to accept the challenge. 
The purpose of the study was to identify, measure, and analyze specific "quality of life" variables and to assess the impact of the city's revitalization efforts on the perceptions of its citizens. The study targeted three population sectors: college students, residents, and visitors. The primary research instruments were questionnaires which utilized mainly closed-ended questions for assessment. Gender and age demographics were included in the questionnaire where it was deemed appropriate. In addition to the questionnaires, the students performed comparative analysis utilizing secondary data sources such as city tourism and visitor information, as well as sundry information from previous projects and similar city revitalization plans executed in Charlotte, NC, Fort Worth, TX, and Milwaukee, WI.

\section{ANALYSIS}

The following is a summary of the questionnaire results and subsequent analysis presented to the client by USC Upstate students.

\section{Residents}

In the residential analysis the city was divided into sections which would be representative of the total population. The students traveled door-to-door, down pre-selected streets, soliciting residents' participation in the project via completion of a questionnaire. Of the 261 residents polled $61 \%$ were female and $39 \%$ male. Age distribution was varied with the majority of respondents aged 50 to 69 .

Most city residents felt the City of Sunshine held a positive perception for others. Approximately half of all respondents believed that the city catered to its "adult" population. Somewhat contradicting this belief was the 66\% who perceived Sunshine as a "college town". Of the residents polled, 79\% agreed or strongly agreed that Sunshine was a good place to raise a family. One aspect of family living, however, is centered on recreational activities. While Sunshine was perceived as family-friendly, the majority of residents felt the city did not do enough to promote or encourage recreational and outdoor activities such as walking, biking, etc.

Residents were generally positive about the city's recent efforts to beautify its existing buildings and landscapes. In fact, the city's enhanced aesthetics were well-received by all three of the groups surveyed. Most residents $(72 \%)$ believed that the city's revitalization efforts would prove beneficial in attracting new residents and encouraging economic development.

The majority of residents traveled outside the city for entertainment and dining purposes no more than three times per month and some $25 \%$ of residents never traveled outside of the city for entertainment or dining purposes at all. A positive correlation with residents' tendency to dine locally was the perception that the number of available restaurants in the city had grown significantly in the past few years.

The overall quality-of-life rating residents gave the city was 7.16 on a scale of $1-10$, with a slight majority awarding a rating of 8 or greater. Younger residents, aged 29 or less, tended to rate the city lower while those aged 50 or older tended to rate it higher. Of the non-retired residents surveyed, 55\% responded they were very likely or likely to remain in the city after retirement. Of the people who had lived in Sunshine less than five years, only $6 \%$ said they would remain in the city after retirement.

Specific to the question "What changes, if any, would you like to see our city move towards in the next five years", the dominant theme for residents was job growth. Complete results of the residents' "Change" question are illustrated in Chart 1. 
Chart 1 - (Residents)

What changes, if any, would you like to see our city move towards in the next five years?

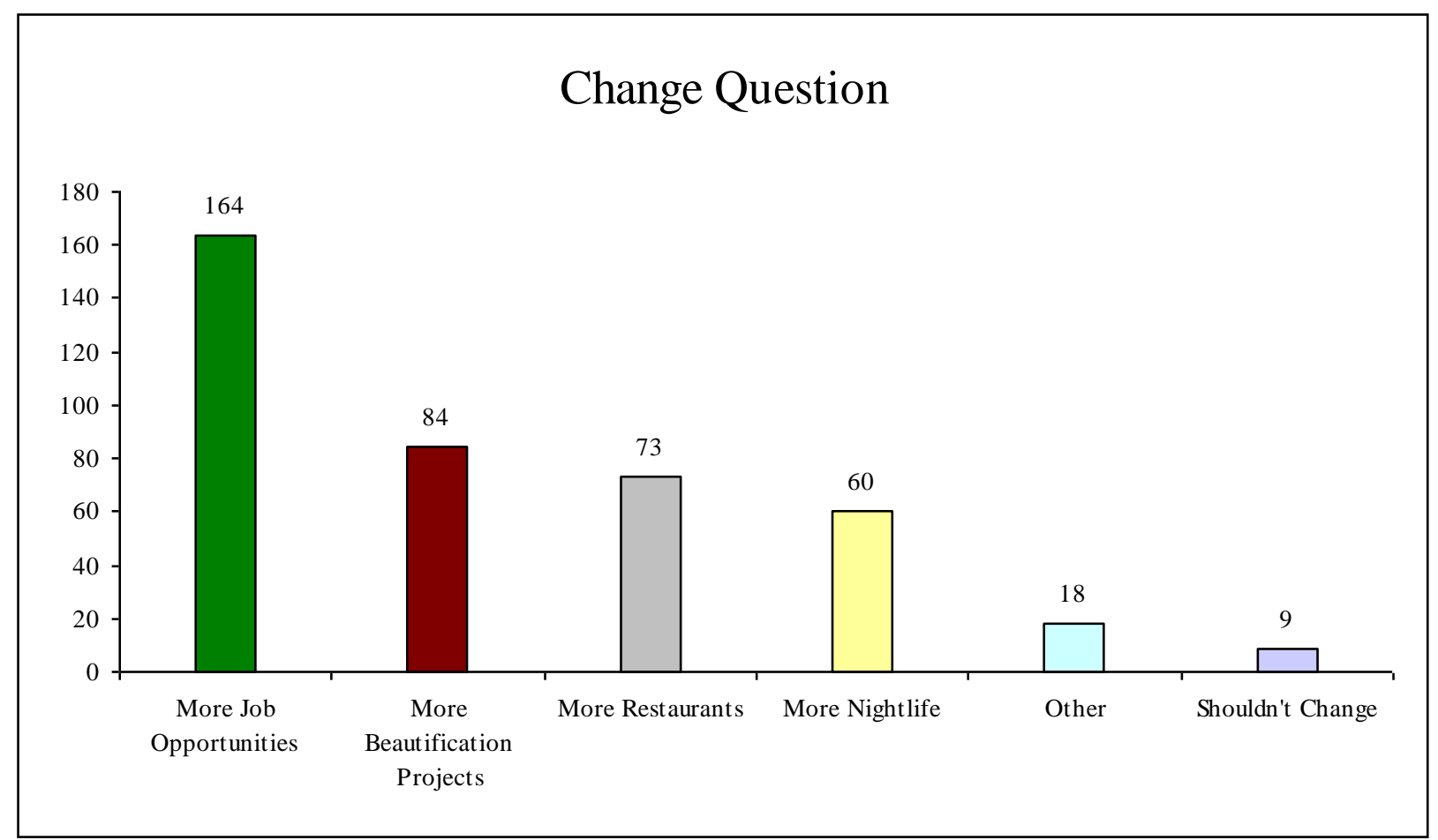

\section{Students}

College students interviewed were $65 \%$ female and $35 \%$ male. No significant age distribution data was collected for student respondents. The percentage of those who had attended high school in the host county was 39\%.

The percentage of students associating Sunshine with prominence in South Carolina was 38\%. Perhaps reflecting the higher number of non-residents within the student population, 39\% of student respondents were neutral as to the "prominence" question. One half of all students believed that Sunshine catered to its adult population while only $22 \%$ had the perception that the city catered to its college age population. Interestingly, like the residential group, $58 \%$ of students agreed that Sunshine is a "college town". This despite the fact that the majority did not feel the city catered to its college-age constituency.

Over $70 \%$ of students agreed that the city was making positive efforts to improve its appearance. Students, however, felt the city did not do enough to promote or encourage recreational and outdoor activities such as walking, biking, etc. Overall, students' perceptions of the city trended more negatively than those of residents. In fact, 39\% of all students gave City X a "quality of life" ranking of 5 or less on a scale of 1-to-10.

Deficiencies in night life options and young-adult events such as concerts, as well as a challenging job market were primary reasons given. Only $30 \%$ of students believed the city provided adequate support for services of interest such as nightclubs and recreational facilities. Job opportunities ranked the highest in terms of environmental change factors cited by students. Overall, the average quality of life rating students awarded Sunshine was 6.12, approximately $14.5 \%$ lower than the residents' average rating. 
Chart 2

How would you rate the quality of life in Spartanburg ( 1 being the lowest and 10 being the highest)?"

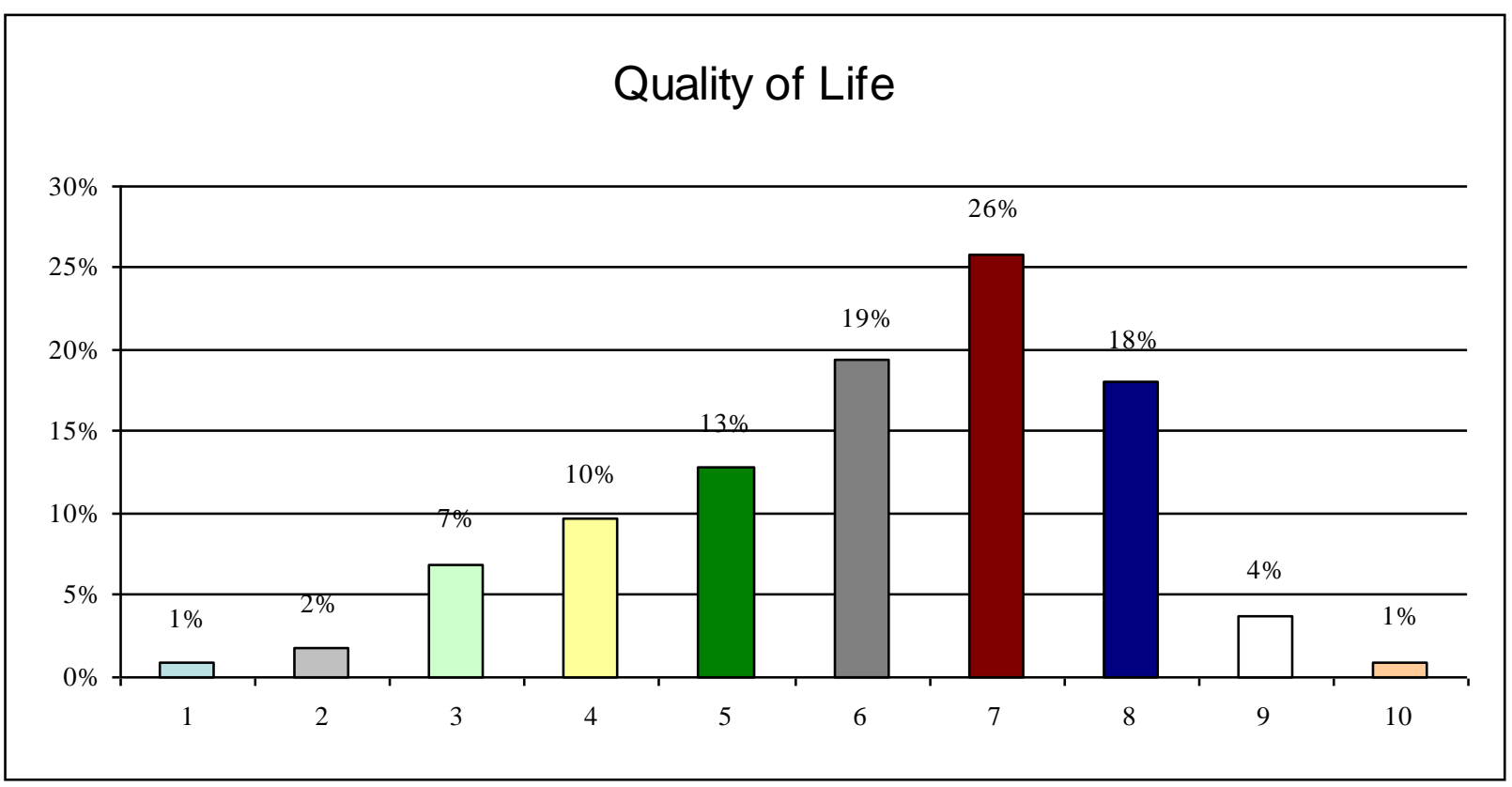

Chart 3

What would be the best addition to XXX based upon what you believe will make the city more appealing? (Choose up to 3)"

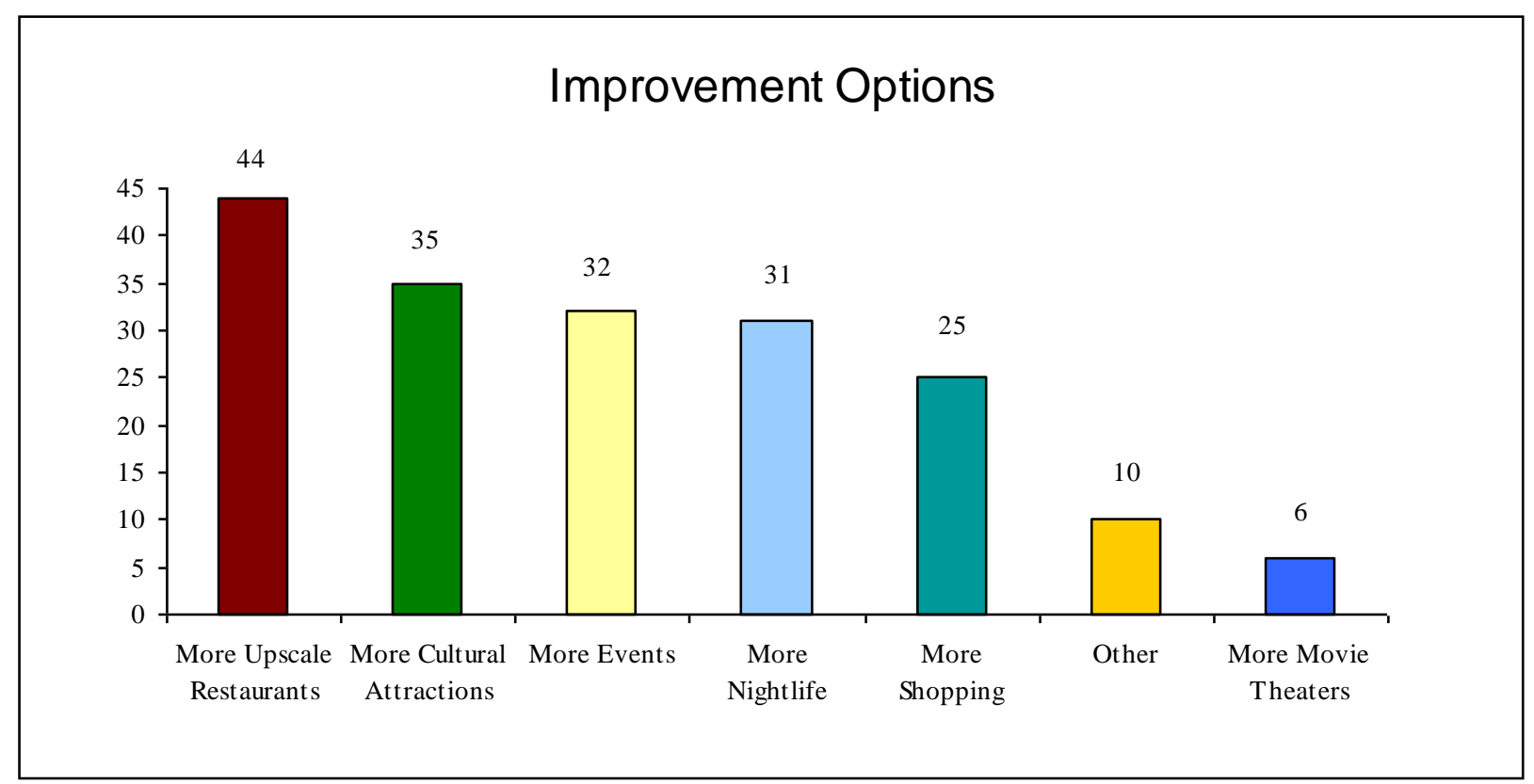




\section{Visitors}

Most visitors surveyed were "repeat" visitors who traveled to Sunshine at least a couple of times per year and from a distance of greater than 50 miles. Many, $64 \%$, were business travelers while another $22 \%$ were in town visiting family members. Of the visitors surveyed, 58\% rated Sunshine as well-known in the southeast. Evidenced perhaps, that the city's marketing of its entertainment venues was either ineffective or inadequate, only $30 \%$ of visitors felt "informed or aware" of Sunshine's entertainment opportunities. This and the results of the "Change" question, illustrated in chart 2, indicated that visitors represent a marketing challenge for Sunshine.

The city's overall relationship with its visitors trended positive, however. On average, visitors rated Sunshine higher (8.62) than the either of the other two groups in terms of "quality of life" perception.

\section{GENERAL OBSERVATIONS}

In addition to specific analysis, students noted several overriding trends and offered these observations to the client during the presentations.

1. The City of Sunshine has a reputation of catering to its adult population. However, students defined an adult as someone aged 30 and up. Because the question "To what group does Sunshine cater to?" did not define the range of the age categories, an interviewee may have interpreted adulthood as something different so the question produced ambiguous results which collided with the "college town" question. This discovery provided an invaluable lesson for the students regarding the dangers of "undefined answers" to closed-ended questions.

2. Residents and students have a positive perception of the city's attempts to improve its appearance and infrastructure. Residents in particular felt strongly that the improvements would help attract new citizens.

3. Both resident's and student's felt the quality and variety of outdoor activities needed improvement. Ongoing efforts to address this deficiency have resulted in a recent honorable mention from the League of American Bicyclists as a "bike friendly" town. The city has now shifted part of its annual budget from beautification projects to "walking and biking" initiatives.

Students designed one question utilized an allegory to assess interviewees' overall opinion of the City of Sunshine. The result was the question, "If Sunshine were a car what kind would it be? Why?" Most cited any "hard working, reliable automobile as representing the City of Sunshine. The Ford F150 pickup, for example, was a popular response. Older individuals felt Buick and Cadillac sedans were good representative automobiles. There were few, if any, exotic or foreign cars offered. This question was well-received by the client.

\section{OPPORTUNITIES}

Aside from the invaluable experience garnered by students, this project generated significant goodwill between the university and the City of Sunshine. After presenting to the Director of Marketing, the students were invited to, again, present their findings, this time to the City's Chamber of Commerce at its December 2005 meeting. Following the very successful Chamber presentation, the Mayor of Sunshine's office generated a letter of appreciation to John Stockwell, USC Upstate Chancellor, thanking him for the "excellent service" the School of Business and Economics had provided to the city. The School was also informed that the student's work would be used as a basis for future Sunshine studies.

Subsequent research opportunities have begun to emerge as "word of mouth" has spread among constituents. The current SBAE 457 course is providing research for a university directed initiative funded through a federal grant. That research attempts to collect information that will be used to identify education strategies to empower residents of Sunshine's Southside, a predominately poor section of the city. There has also been inquiry from Sunshine's United Merchants Association for research services. 
Public receptivity to undergraduate marketing research is spurring Sunshine's business school to explore the potential expansion of its research curriculum. The faculty curriculum committee is currently assessing the viability of adding a "Research" course(s), devoted entirely to business research practicum, to support and foster undergraduate research initiatives throughout the Upstate area of South Carolina.

\section{REFERENCES}

1. SBAE 457 Marketing Research Class (2005, December 10). A Market Research Project. Presented at the City of Spartanburg Chamber of Commerce Meeting.

2. Morrison, Alan, (April 24,2006), Spartanburg on the path to being bicycle-friendly, GoUpstate.com, Retrieved August 28, 2006 from: http://www.goupstate.com/apps/pbcs.dll/article?AID=/20060424/NEWS $1604240305 \&$ SearchID $=73244850052268$ 